Elsevier required licence: (C) <2018>. This manuscript version is made available under the CC-BY-NC-ND 4.0 license http://creativecommons.org/licenses/by-nc-nd/4.0/ 


\title{
Organizational improvisation and the reduced usefulness of performance measurement BI functionalities
}

\author{
Matt D. Peters ${ }^{\mathrm{a},{ }^{*}}$, Bernhard Wieder ${ }^{\mathrm{b}}$, Steve G. Sutton ${ }^{\mathrm{c}}$. \\ a Accounting Cluster, The University of Queensland, Brisbane QLD, 4072, Australia. Email: \\ m.peters@business.uq.edu.au.Telephone: 61 (7) 33463451. \\ ${ }^{\mathrm{b}}$ Accounting Discipline Group, University of Technology Sydney, P.O. Box 123, Broadway NSW \\ 2007, Australia.
}

c Kenneth G. Dixon School of Accounting, University of Central Florida, P.O. Box 161400, Orlando, FL 32816, United States.

${ }^{*}$ Corresponding author.

\begin{abstract}
Firms are increasingly turning to business intelligence (BI) systems to support their management control activities, while management accounting researchers are increasingly focused on studying beneficial roles of such systems. The extant research focusses on how performance-enhancing effects of BI systems occur via enhanced managerial learning and knowledge creation. The research has however failed to consider how managerial learning and knowledge creation processes can be shaped by fundamental organizational contingencies. This paper ventures into this unexplored space to consider how organizational improvisation may moderate beneficial roles played by BI. We derive the concept of 'semi-structuring heuristics' and apply it to theorize that the impact of BI functionalities on performance measurement capabilities is negatively moderated by organizational improvisation. Our hypotheses include two BI constructs (BI-planning functionality and BI-reporting functionality) and two organizational improvisation competences (strategic momentum and organizational flexibility). We test our hypotheses with partial least squares procedures using survey data from 324 top-level managers. We find that BI-planning functionality has a positive effect on performance measurement capabilities that is negatively moderated by both organizational improvisation competences. The only significant effect of BI-reporting functionality is as a positive moderator of the effect of BI-planning functionality. Organizational improvisation competences are quite common and entail managers using only 'minimal forms' of performance measurement information. By implication, if the term BI 'functionality' connotes usefulness and fitness-for-purpose, then this term appears a misnomer in contexts reliant on organizational improvisation.
\end{abstract}

\section{Keywords}

Business intelligence (BI) systems; organizational improvisation; management control systems; organizational flexibility and strategic momentum; performance measurement; planning and reporting systems.

\section{Highlights}

- Contributes to the literature regarding roles of various BI and management control systems in strategy and learning.

- Sheds light on how organizational improvisation competences (strategic momentum and organizational flexibility) reduce BI usefulness.

- Reveals insights into the separate and joint effects of BI-planning functionality and BIreporting functionality. 


\section{Introduction}

Management accounting researchers have increasingly focused on the role of business intelligence (BI) in packaging and enhancing management control systems. ${ }^{1}$ The emerging literature links BI to positive organizational outcomes via beneficial roles in performance measurement capabilities and interrelated organizational learning processes (Elbashir et al., 2008, 2011, 2013; Lee and Widener, 2016; Peters et al., 2016; Prasad and Green, 2015). The overarching emerging perspective is that BI functionality provides more performance measurement data, which enables more managerial processing of performance measurement information, which leads to more managerial and organizational learning (e.g., Peters et al., 2016). However, research has not addressed the lingering issue of whether such beneficial roles of BI functionality vary in conditions of heightened strategic and adaptive action (Chapman and Kihn, 2009; Orlikowski, 1991).

The purpose of this study is to examine whether the usefulness of BI functionality is altered by competences for organizational improvisation. We study two specific competences for organizational improvisation: strategic momentum (for enacting strategic action) and organizational flexibility (for enacting adaptive action). In the domain of practice it is often argued (for example by BI software vendors) that such competences are enhanced by BI functionality (Kiron et al., 2012), while in academic literature remains an open question (Chapman and Kihn, 2009). These two competences also warrant study because they are important: they can be sources of competitive advantage and can lead to substantial organizational development over time (Argote, 2013; Crossnan et al., 2005; Orlikowski, 1996).

1 The term business intelligence (BI) refers broadly to management support systems for gathering, storing, and accessing data for decision making (Clark et al., 2007). BI systems are distinct from executive information systems, knowledge management systems and decision support systems (Clark et al., 2007). In this paper we use the term BI in reference only to the category that is specific to business unit performance measurement (Chaudhuri et al., 2011). Other types of BI - such as data mining, predictive analytics and text analytic engines (Chaudhuri et al., 2011) - are outside the scope of this research. 
This research is grounded in organizational improvisation theory (Bingham and Eisenhardt, 2011; Brown and Eisenhardt, 1997; Crossnan et al., 2005; Cunha et al., 2015; Kanoche and Cunha, 2001). Organizational improvisation is a polymorphous concept of which we focus on semi-structured forms, as they have the clearest links to performance measurement capabilities (Brown and Eisenhardt, 1997; Cunha et al., 2015). We conceptualize strategic momentum (Miller and Friesen, 1980) and organizational flexibility (Volberda, 1996) as the creativity and spontaneity variants of semistructured organizational improvisation respectively (Crossnan et al., 2005; Cunha et al., 2015). We derive and apply the concept of semi-structuring heuristics: managerial hierarchies learn competences for semi-structured improvisation (Cunha et al., 2015), including heuristics (Bingham and Eisenhardt, 2011) used when processing performance measurement information. When applying semi-structuring heuristics managers process only minimal forms of performance measurement information. These minimal forms provide minimal structures for the processes of enacting improvisation (Kanoche and Cunha, 2001; Weick, 1989).

Our hypotheses examine the effects of BI-planning functionality and BI-reporting functionality separately (Peters et al., 2016). The prior research has studied BI functionality as a higher-level construct that combines BI-planning with BI-reporting. In this study these two types of BI are disentangled, because of potential differential effects in light of organizational improvisation, and also in case of potential implications for BI adoption decisions for practitioners. For each type of BI, functionality ranges from 'low' (spreadsheet-based) to 'high' (specialist applications). Our theorizations lead to hypotheses in which positive effects of BI-planning functionality and BIreporting functionality are expected to be negatively moderated by competences for organizational improvisation.

We test the hypotheses with survey data from top management team members representing 324 business units, using structural equation modelling-partial least squares (SEM-PLS) procedures. We find that BI-planning functionality has a positive main effect on performance measurement 
capabilities, and that this effect is negatively moderated by both strategic momentum and organizational flexibility. BI-reporting functionality exhibits no such main or moderated effects. We also find a positive joint effect of BI-planning functionality and BI-reporting functionality. In summary, we find that the positive effect of BI-planning functionality is reduced by organizational improvisation, and enhanced by BI-reporting functionality.

This study extends the performance measurement capabilities and BI functionality section of the theoretical model put forth in Peters et al. (2016) in two important ways. First, this study separately examines the effects of BI-planning functionality and BI-reporting functionality on performance measurement capabilities. The prior literature views these functionalities as working in concert, but ignores the differences across the two aspects of functionality as organizational contingencies vary. BI systems are not a monolith and clarifying conceptual distinctions is important, not least because clear concepts are fundamental to strong and clear theories (Suddaby, 2010). This study clarifies that BIreporting functionality only impacts performance measurement capabilities by positively moderating the effect of BI-planning functionality. Thus, this study enhances our understanding of how BI-based management control systems design concepts relate to performance measurement capabilities.

The second way that this study extends Peters et al. (2016) is by contributing a moderating-effects logic based on competence-based heuristics. With the semi-structuring heuristics notion we develop a moderating-effects logic that helps mature the literature beyond its sole reliance on mediation models (Chapman and Kihn, 2009; Elbashir et al., 2008, 2011, 2013; Lee and Widener, 2016; Peters et al., 2016; Prasad and Green, 2015). This moderating-effects logic embraces contemporary views that perceive heuristics as rational rules of thumb that guide organizational processes and competences, and rather than being just cognitive shortcuts such heuristics can be more effective than informationintensive approaches to organizing (Bingham and Eisenhardt, 2011). This is in step with the broader referral literature where contingency factors are evolving from traditional entitative (i.e., 'static) views of structure to processual competences for structuring (McGrath, 2006). This theory advancement also 
provides a complementary perspective to Lee and Widener (2016) who articulate how managerial cognition is shaped by the qualities and quantities of data available from BI systems. Competencebased heuristics explain how the cognitive processes involved in using BI systems can also be socially constructed from the process experiences of the organization (Bingham and Eisenhardt, 2011).

This study also has implications for practice. Vendors often assert that high functionality BI systems provide higher quality information for strategic decision making and organizational flexibility (Kiron et al., 2012). Yet, as Elbashir et al. (2013) note, there are many reports of disappointment following BI systems implementations in practice. The results of this study indicate that high functionality BI systems are of very limited usefulness for performance measurement capabilities in contexts where organizational improvisation is prevalent. By implication, the potential importance of BI functionality for enhancing organizational performance (e.g., Peters et al., 2016) is also much reduced in contexts where organizational improvisation prevails. Our data shows that competences for organizational improvisation are quite common. In firms that are in the early stages of developing competences for organizational improvisation, managers need to learn to select and process only minimal forms of performance measurement information, and to disregard highly detailed multi-dimensional data models from higher functionality BI systems if such systems are implemented. Given that significant resource commitments can be required for implementing, staffing and maintaining the BI integrated infrastructures and specialized applications needed for high quality BI systems (Lee and Widener, 2016; Peters et al., 2016), the results from this study also suggest that BI-planning systems quality should be prioritized over BI-reporting systems quality.

This paper has four remaining sections. Section 2 develops the theoretical model and hypotheses. Section 3 presents the research method. Section 4 presents the hypotheses test results. Section 5 summarizes the results and provides some concluding thoughts on the study. 


\section{Theory development and hypotheses}

In this study we take a closer look at the robustness of the positive link between BI functionality and performance measurement capabilities from the mediation model studied in Peters et al. (2016). We examine the robustness of this link in two ways. First, we deconstruct the two-dimensional emergent construct of BI functionality into the two separate constructs of BI-planning functionality and BIreporting functionality. Second, we consider the moderating effects of organizational improvisation on the links between BI functionality and performance measurement capabilities. Overall we use a refined set of BI constructs that provide a more optimal conceptualization from which to study the potential for the positive impact from BI functionality to be moderated by organizational improvisation. Following on from Peters et al. (2016), the dependent variable is performance measurement capability, which is the extent to which a business unit's managerial hierarchy routinely processes performance measurement information (Simons, 1995). These performance measurement routines are for planning (during annual budgeting and for monthly (re)forecasting) and resultsreporting, and they can be interactive (based on multi-level managerial debate) or diagnostic (for reinforcing performance aspirations) (Peters et al., 2016; Simons, 1995).

BI functionality is the capacity of the user interface for processing performance measurement data (Peters et al., 2016). BI functionality depends strongly on BI infrastructure integration; that is, firms tend to have levels of data availability from source systems that match the functionality levels of their BI applications (Peters et al., 2016). BI functionality is the usability level for modeling and interacting with multi-dimensional data hierarchies. Drawing from Ariav (1992), Peters et al. (2016) outlined the properties of usability and data multi-dimensionality. Usability requires unified access and user manipulation of and between current, historic and future data cubes, where cubes comprise objects, attributes and time. Second, multi-dimensionality refers to the extent of objects, attributes and temporality. Objects include responsibility center arrays (e.g., profit center, revenue center, cost center), responsibility center aggregation patterns (e.g., manager, regional, national), and plan versions (e.g., actual results, budget, forecast, latest forecast). Attributes refer to calculative elements 
(e.g., amounts, stock keeping units, employees). Temporal dimensionality refers to time periods (e.g., day, month, quarter, or year). Peters et al. (2016) establish a strong direct link between BI functionality and performance measurement capabilities.

BI-planning and BI-reporting systems are both needed for a performance measurement system, a type of contemporary management control system incorporating financial and non-financial data (Peters et al., 2016). BI-planning and BI-reporting systems together facilitate the cybernetic feedback loops that are a hallmark of formal management control systems. Practically every business unit has at least 'low' levels of BI-planning functionality and BI-reporting functionality (Peters et al., 2016). With 'low' functionality, user modeling and data interaction occur in spreadsheet applications (e.g., Microsoft Excel). Spreadsheet applications permit only minimal interactive interfacing with object and attribute multi-dimensionality, along with only minimal switching between time dimensions and plan versions. In contrast, with 'high' functionality, advanced design properties inherent to specialist applications (e.g., Cognos, Hyperion etc.) enable greater ease, extent, and speed of structured data processing for multi-dimensional hierarchical models (Ariav, 1992; Peters et al., 2016). High functionality BI systems provide highly detailed performance measurement data, leading to a myriad of possible performance reports and an exhaustive array of performance metrics (Elbashir et al., 2011) that managers could potentially use.

Our theorization views BI functionality as being more useful if it enhances learning for more tightly structuring business unit coordination and integration. The managerial knowledge created from the learning processes within performance measurement capabilities provide structuring for enacting business unit coordination and integration (Chandler, 1962; Galunic and Eisenhardt, 1994; McGrath, 2006; Merchant and Van der Stede, 2012; Simons, 1995). Business unit coordination and integration are how business sub-units work together to perform their tasks and activities (Barki and Pinsonneault, 2005; Thompson, 1967). We view managerial knowledge for business unit coordination and integration as being an essential product of the learning processes within performance 
measurement capabilities. This perspective builds upon the prior literature's emphasis on organizational learning as the overarching mechanism by which BI systems enhance managerial control activities (e.g., Elbashir et al., 2008, 2011, 2013; Lee and Widener, 2016; Peters et al., 2016; Prasad and Green, 2015). We argue that highly multi-dimensional data elements from BI systems will only be processed as information by managers when they perceive such highly granular data as potentially useful (Alavi and Leidner, 2001; Huber, 1991; Peters et al. 2016) for structuring business unit coordination and integration.

In the following two sections we develop hypotheses that build on the theoretical underpinnings outlined above. First, we argue that BI functionalities strengthen performance measurement capabilities because they can be used to achieve tighter business unit coordination and integration. We develop hypotheses for the main and joint effects of BI-planning functionality and BI-reporting functionality. Second, we argue that the main effects of BI-planning functionality and BI-reporting functionality are negatively moderated by organizational improvisation. Organizational improvisation involves business unit integration and coordination that relies on minimal structures (Cunha et al., 2015) that need only relatively minor forms of performance measurement data. We develop hypotheses for two organizational improvisation competences: strategic momentum (for creativity) and organizational flexibility (for spontaneity). The competences are argued to include distinct semistructuring heuristics that shape how managers process minimal forms of performance measurement information.

\subsection{BI functionalities}

Higher BI functionalities provide a more detailed digitized rendering of a business unit (Peters et al., 2016). This entails more individual data elements that could be processed by managers for (re)figuring performance plans or analyzing performance outcomes. Those more detailed data models and sophisticated usability features provide information content that frames and shapes managerial decision making towards business unit coordination and integration. Thus, we expect that higher BI 
functionality provides higher quantities of performance measurement data, which can enable more performance measurement information processing, thereby strengthening performance measurement capabilities.

The importance of $\mathrm{BI}$ functionality for structuring business unit coordination and integration is a theme implied in several prior studies. Chapman and Kihn (2009) found that information systems integration (i.e., a single data source for financial and non-financial information) enhances repair, local transparency and global transparency when senior managers process information from management control systems. Repair refigures budgets and forecasts to better coordinate future activities, while local and global transparency provides sub-unit and business unit-wide contextual information for managers to reintegrate business sub-units. In other related literature, the Elbashir et al. (2011) concept of BI assimilation shows that BI information is typically absorbed evenly across the three functions of operations, customer service and marketing - also implying enhanced sub-unit integration and coordination.

BI-planning systems are for producing performance plans (e.g., annual budgets or monthly (re)forecasts). With higher functionality, the performance measurement data structures are more multi-dimensional, with more interrelated data arrays, providing opportunities for a managerial hierarchy to plan for tighter coordinative and integrative activities within and across business subunits (Galbraith, 1977). If members of a managerial hierarchy are personally involved in populating such detailed data fields their greater information processing will strengthen the business unit's performance measurement capabilities. This leads to the first hypothesis:

H1a: BI-planning functionality enhances performance measurement capabilities.

BI-reporting systems provide actual performance data and feedback variance data, for analysis, distribution and information processing by a managerial hierarchy (Peters et al., 2016). Higher BI- 
reporting functionality provides more customizable online reports, more sophisticated formats and presentation features, and enables more multi-dimensional slicing-and-dicing of data (Peters et al., 2016). With higher BI-reporting functionality, real-time performance data is also usually more readily available from underlying transactional systems through BI integrated infrastructure (Peters et al., 2016). These advanced design features enable a broader and timelier distribution of results and feedback information compared to static reporting formats and low functionality systems (e.g., Dilla et al., 2010). Thus, higher BI-reporting functionality provides a managerial hierarchy with greater visibility of deviations from planned coordinative and integrative activity patterns. This greater visibility can facilitate more performance measurement information processing by a managerial hierarchy for identifying coordinative and integrative problems requiring their attention. Therefore, we hypothesize that:

H1b: BI-reporting functionality enhances performance measurement capabilities.

BI-planning functionality and BI-reporting functionality are expected to also enhance performance measurement capabilities via a positive joint effect. This joint effect could be labeled 'feedback functionality' and arises because the feedback-baseline data in a BI-reporting system flows from a BIplanning system. With greater BI-planning functionality, cybernetic baseline data is more multidimensional. With this joint effect, additional feedback data elements are therefore available. This facilitates more detailed variance interpretations, which can then be used to articulate further aspects of business unit performance, leading to a greater understanding amongst a managerial hierarchy about how effectively business unit activities were coordinated and integrated. Thus, with a combination of higher levels of BI-planning and/or BI-reporting functionality, enhanced in-depth performance feedback data is more frequently available. With the expectation that this will lead to improved processing of feedback information by a managerial hierarchy, the following can be hypothesized: 
H1c: BI-planning functionality and BI-reporting functionality have a positive joint effect on performance measurement capabilities.

\subsection{Organizational improvisation}

In this section we build on the notion that business unit coordination and integration in contexts of organizational improvisation relies on minimal structures (Kanoche and Cunha, 2001). We focus on the semi-structured forms of improvisation, which are the most formal of the four forms of improvisation (resistive, subversive, episodic and semi-structured) identified by Cunha et al. (2015). The semi-structured form has been uniquely articulated as relying on minimal structuring from the formal use of performance measures (Brown and Eisenhardt, 1997). Semi-structured improvisation has been identified as salient to new product development (Brown and Eisenhardt, 1997), dynamic capabilities (Eisenhardt and Martin, 2000), emergent strategy and strategic decision making (Crossnan et al., 2005, Cunha et al., 2015), organizational learning and renewal (Kanoche and Cunha, 2001) and continuous bottom-up adaptation and strategic learning (Cunha et al., 2015).

To relate competences for organizational improvisation to the use of BI functionalities we derive and apply the concept of semi-structuring heuristics. From their process experience, organizations learn competences for improvisation (Cunha et al., 2015), which include heuristics for re-enacting that form of improvisation (Bingham and Eisenhardt, 2011). In a traditional sense, heuristics are viewed as cognitive shortcuts that emerge when information, time and processing capacity are limited (Newell and Simon, 1972). Yet in the context of semi-structured improvisation (Brown and Eisenhardt, 1997), heuristics constitute locally constructed rational rules of thumb that guide action (Bingham and Eisenhardt, 2011). Heuristics can be far more effective than information-intensive, cognitively demanding approaches to organizing (Bingham and Eisenhardt, 2011). Heuristics are learned as business unit managers draw inferences and gain insight from the outcomes of their actions (Bingham and Eisenhardt, 2011). 
Details of improvised action can be ambiguous and unpredictable, yet they can be minimally planned for and formally evaluated (Brown and Eisenhardt, 1997) with semi-structuring heuristics. Managers will have learnt to automatically process BI-planning data with a mindset that accepts the ambiguity and unpredictability inherent to improvisation. They also will have learnt to automatically process BIreporting data with a mindset that seeks to evaluate results in the light of ambiguous and unpredicted improvisational actions experienced. Due to the recurring nature of cybernetic feedback loops in performance measurement capabilities (Peters et al., 2016), heuristics for processing BI-planning information will develop reflexively with the heuristics for processing BI-reporting information. In developing competences for organizational improvisation, managers will learn that, just as it is ineffective to be intensively involved in selecting highly detailed performance plans, it is ineffective to process highly detailed and comprehensive performance variance data and reports.

There are two variants of semi-structured improvisation competences, creativity and spontaneity (Crossnan et al., 2005; Cunha et al. 2015), which we operationalize with the respective constructs of strategic momentum and organizational flexibility. With these two specific constructs we study what are otherwise highly abstract concepts that Cunha et al. (2015) created with their synthesis of the organization improvisation literature. Strategic momentum entails improvisational processes that elaborate upon an established strategic mission by incorporating novel solutions to emerging problems (Miller and Friesen, 1980; Turner et al., 2013). Strategic momentum is related to the creativity variant which Cunha et al. (2015: 516) describe as processes that 'embellish the original structure, incorporating novel solutions to emerging problems'. Organizational flexibility is for correcting failures in planning and for fixing operational deficiencies that require immediate action (Denison and Mishra, 1995; Volberda, 1996). Organizational flexibility is related to the spontaneity variant which Cunha et al. (2015: 516) describe as processes that 'respond to spontaneous departures and unexpected opportunities'. 
Competences for strategic momentum and organizational flexibility, therefore, include semistructuring heuristics. To have a competence for improvisation implies that a business unit has also developed the particular forms of performance measurement capabilities that provide semi-structured support for that competence. Semi-structuring heuristics operate in performance measurement capabilities to use performance measures as minimal structures. Minimal structure provides general assumptions and incomplete expectations (Weick, 1989) that guide complex, interrelated improvisational actions, allowing freedom within flexible ranges and tolerances (Kanoche and Cunha, 2001). Rather than prescribe rigid courses of action, minimal structure provides simple structures for coordinating strategy-making action and organizational flexibility (Crossnan et al., 2005). Minimal structure includes minimal forms of performance measurement information that semi-structure coordinative and integrative patterns of activity (Kanoche and Cunha, 2001). Minimal forms of performance measurement information can be used to effectively communicate proactive or reactive issues (Crossnan et al. 2005), for shaping, prioritizing and guiding improvisation (Brown and Eisenhardt, 1997). Minimal forms provide parsimonious and concise accountability parameters (Orlikowski, 1996) to support network effects and high-level interdependencies (Kanoche and Cunha, 2001). Minimal forms can effectively semi-structure the participation needed for the details of improvisational action to emerge over time (Cunha et al., 2015; Mintzberg, 1987).

It follows that minimal forms of performance measurement information require only low functionality BI systems. It can be surmised that in processing minimal forms, only large 'chunks' of performance data are perceived as useful. In their processes of searching and filtering through performance measurement data, were high functionality BI systems implemented, semi-structuring heuristics would be used to filter out the large volumes of data as extraneous. With such performance measurement processes, a managerial hierarchy only focuses on higher level performance measures. Thus, in firms with improvisational competences, the highly detailed coordinating schedules and integrational sequencing patterns provided by high functionality BI are not salient to performance measurement capabilities. In contexts of organizational improvisation, performance planning and 
reporting routines are serviceable with low functionality BI systems. Were high functionality BI implemented, the sophisticated features for interacting with highly multi-dimensional data models would go unused by managers in their selecting, processing and communicating of information in performance measurement capabilities.

Our first set of moderating effects hypotheses are concerned with strategic momentum. The strategic momentum form of improvisation is a competence to enact an established and consistent strategic mission (Miller and Friesen, 1980; Mintzberg, 1987; Turner et al., 2013). We view strategic momentum as collective action and decision making that is based on a common mindset that encompasses a clear purpose, direction, and vision (Denison and Mishra, 1995). With strategic momentum, while a strategic mission provides a solid structure for action, there are progressive development practices over time that are unpredictable and ambiguous (Mintzberg, 1987; Turner et al., 2013). Strategic momentum practices typically involve programs to introduce new market or operational innovations, requiring coordination with suppliers, customers and human resources (Turner et al., 2013).

Semi-structuring heuristics inherent to strategic momentum emphasize the manipulation, active planning, and execution of strategic action (Crossnan et al., 2005). Strategic momentum synchronizes the pace of the organization through processes of improvisational change, patterned by high-level schedules that specify timing, people, and money to be spent on projects, tasks and activities (Crossnan et al., 2005). Rather than require highly detailed performance measures, strategic momentum relies on minimal forms that specify performance criteria and accountabilities that are simple, yet serious (Orlikowski, 1996). Strategic momentum cannot be planned for and tracked in detail (Crossnan et al., 2005) because the details of action require situated improvisations that are ambiguous and unpredictable (Orlikowski, 1996). To enact strategic momentum, highly detailed coordinating schedules and integrational patterns are not salient to performance measurement capabilities. Thus, we expect that strategic momentum reduces the effectiveness of BI functionalities 
for performance measurement capabilities. This is because the enacting minimal forms of performance measurement information require only low functionality BI systems. This leads to the following hypotheses:

H2: Strategic momentum negatively moderates the effects on performance measurement capabilities of:
a. BI-planning functionality

b. BI-reporting functionality

Organizational flexibility is conceptualized as a competence to enact responses to unexpected events (Arnold et al. 2015; Crossnan et al., 2005; Volberda, 1996). Organizational flexibility involves decentralized decision making, an acceptance of risk-taking, a tolerance for unpredictable error, and can result in outcomes that are emergent and surprising (Denison and Mishra, 1995; Mintzberg, 1987). As stated, we link organizational flexibility to the spontaneity dimension of semi-structured improvisations, because consistent with Cunha et al. (2015) it is useful for correcting failures in planning and for fixing operational deficiencies that require immediate action.

Organizational flexibility entails making retrospective sense of unexpected events, assessing reactions taken, and progressing by synchronizing plans for the future with adaptive changes if required (Crossnan et al., 2005). This contrasts with managers believing that the future has a continuous relationship with the past and extrapolate in detail plans for the future from details of the past (Crossnan et al., 2005). Organizational flexibility emphasizes attuning unexpected experiences from the past into plans to adapt the business unit more effectively into the future (Crossnan et al., 2005). Planning in such a context entails concerted efforts to adapt and to prepare the organization for future contingencies. Hence, we surmise that semi-structuring heuristics for organizational flexibility are essentially future-oriented - expecting the unexpected, and learning from and adapting to unexpected experiences. 
To plan for the unexpected, whilst also learning from the unexpected, requires only minimal forms of performance measurement information processed by a managerial hierarchy. Minimal forms proactively anticipate contingencies and include allowable margins for error to accommodate flexible responses if needed (Crossnan et al., 2005). Such minimal forms do not require highly multidimensional performance data models because tightly integrated data structures involve too many unresolvable permutations and overly complicated interrelated action possibilities and actualities. Rather than processing micro-level datasets from high functionality BI-planning and BI-reporting systems, a managerial hierarchy will process only minimal forms of performance measurement information, to select and draw out macro issues requiring follow-up action. Therefore, the effects of BI functionalities upon performance measurement capabilities will be reduced by organizational flexibility, because the enacting minimal forms of performance measurement information are available from lower functionality BI systems. This leads to the following hypotheses:

H3: Organizational flexibility negatively moderates the effects on performance measurement capabilities of:
a. BI-planning functionality

b. BI-reporting functionality

\section{Research method}

A cross-sectional survey was administered to top-level managers of Australian-based business units. ${ }^{2}$ Conventional design and administration procedures were used, including pre-testing with five academics and four practitioners (Dillman, 2007; Netemeyer et al., 2003; Tourangeau et al., 2000). The survey was administered to 1,607 target respondents using postal and internet modes (Dillman, 2007). The mailing list was purchased from a commercial provider using a random sampling procedure. If the role of a particular respondent spanned multiple business units, the respondent was asked to consider the largest business unit only.

\footnotetext{
2 The dataset is the same as used in Peters et al. (2016).
} 
The survey was conducted in four rounds, generating 507 responses ( $31.6 \%$ response rate) with 430 complete responses. Responses from managers with less than one year of tenure were excluded, to ensure that all respondents in the test sample had enough time to be knowledgeable about the BI systems and performance measurement capabilities in their organization. Given that performance measurement capabilities are often not a feature of small firms, we removed responses from business units that had less than 100 employees (Bisbe and Otley, 2004; Henri, 2006). The final sample consisted of 324 responses. The respondents were chief financial officers or other senior finance managers (61.1\%), with the remainder being chief executive officers and general managers. In line with Australia's sectoral structure, $70.1 \%$ of responses were from services firms and $29.9 \%$ were from manufacturing firms.

\subsection{Construct measurement}

All survey instruments for the constructs were sourced from prior literature. Appendix A provides the survey measurement items.

BI planning functionality (BI-PLANNING) refers to the level of usability and multi-dimensionality of a planning user-interface application, such that higher functionality enables faster creation and revision of budgets and forecasts with greater data multi-dimensionality (Peters et al., 2016). BI reporting functionality (BI-REPORTING) refers to the level of usability and multi-dimensionality of a managerial reporting application, such that higher functionality provides additional customizable reports, sophisticated formats, and presentation features, and multi-dimensional data structuring (Peters et al., 2016). BI-planning functionality and BI-reporting functionality were each measured with four reflective items, using the instruments developed by Peters et al. (2016). Likert scale scores were coded from 1 to 5 , with 5 representing high functionality. 
Performance measurement capabilities (PERF-MEASURE-CAPABILITY) were measured with a twodimensional emergent construct, those dimensions being: (1) interactive performance measurement capabilities; and (2) diagnostic performance measurement capabilities (Peters et al., 2016; Simons, 1995). Each of these two dimensions was measured with a two-dimensional emergent model, with those lower-order constructs being: (1) profit-planning information; and (2) non-financial key performance indicators (Malmi and Brown, 2008). Each of the four lower-order constructs was reflectively measured with four survey items from prior literature (Abernethy and Brownell, 1999; Bisbe and Otley, 2004; Naranjo-Gil and Hartmann, 2007; Widener, 2007). The scores for interactive performance measurement capabilities and diagnostic performance measurement capabilities were coded from 1 to 5 and 1 to 7 respectively, with higher scores indicating higher degrees of performance measurement capabilities. The latent variable scores were generated in hierarchical SEM-PLS models as per Wetzels et al. (2009).

Strategic momentum (STRAT-MOM) and organizational flexibility (FLEXIBILITY) are learnt improvisational competences that include heuristics that managers apply for managing improvisation. To measure these competences and constituting heuristics we used conceptually aligned measures of organizational culture values (Denison and Mishra, 1995), which, like heuristics, reflect socially constructed cognitive schemata (DiMaggio, 1997) that shape habits of thinking, mental models and shared meanings (Weber and Dacin, 2011). To operationalize strategic momentum and organizational flexibility values, we used measures of such phenomena in existing organizational competences (Denison and Mishra 1995; Weber and Dacin, 2011). Organizational flexibility (Volberda, 1996; Denison and Mishra, 1995; Arnold et al. 2015) was conceptualized as competences for improvisations that respond to spontaneous departures and unexpected opportunities (Crossnan et al., 2005; Cunha et al., 2015) and was measured with four reflective items: two for adaptability behaviors and two for participative involvement behaviors (Denison and Mishra, 1995; Fey and Denison, 2003). Strategic momentum (Miller and Friesen, 1980; Turner et al., 2013) was conceptualized as a competence for 
improvisation that embellishes an established strategic mission by applying novel solutions to emergent action (Crossnan et al., 2005; Cunha et al., 2015) and was measured with four reflective items: two for strategic mission and two for strategic consistency (Denison and Mishra, 1995; Fey and Denison, 2003). Scores were coded from 1 to 7 , with 7 representing a strong organizational improvisation competence.

\subsection{Method and non-response biases}

Several procedural remedies were applied to mitigate the potential for method bias following procedures outlined by Podsakoff et al. (2012). To increase a participant's motivation to respond accurately, they were invited to register for a findings report, and the survey was voluntary and anonymous. The potential for risk of inaccurate responses was also mitigated by targeting only toplevel managers, who are likely to be appropriately interested and knowledgeable about the broad range of business unit-wide factors surveyed. The potential effects of media preferences were reduced by contacting all target respondents by both post and email. The number of Likert scale points across constructs was varied and the order of survey items was designed to mitigate the risk that respondents might try to guess the nature of the relationships being studied.

The Harman's single-factor test and the unmeasured latent method factor technique were both used to satisfactorily assess for common method bias (Podsakoff et al., 2012). For the Harman's single-factor test, an exploratory factor analysis of the measurement items resulted in six factors with eigenvalues $>$ 1 and cumulative variance of $71.0 \%$, with the first factor explaining less than half of the overall variance $(35.2 \%)$ - providing evidence against the possibility that common method variance due to single source bias might be present (Podsakoff and Organ, 1986). For the unmeasured latent method factor technique, a covariance-based SEM package (SPSS 22 AMOS) was used. Aligned to the theoretical model, a base model with four exogenous variables (BI-planning functionality, BIreporting functionality, strategic momentum and organizational flexibility) and one endogenous variable (performance measurement capabilities) was estimated. Then a general latent method factor 
(measured by the indicators of all five constructs) was added to that base model, and the four path estimates (between the four exogenous variables and performance measurement capabilities) were all very similar to those in the base model. Hence, the unmeasured latent method factor technique also provides evidence against the possibility of common method bias (Podsakoff et al., 2012).

Non-response bias was assessed by splitting the dataset into two sub-groups that represented the early and late respondents. Independent sample tests (Mann-Whitney $U$ ) of all the test indicators showed no significant sub-group differences. We could not check for this bias by comparing the target sample with the actual response sample, however, because the commercial mailing list provided data at the corporate level while our responses came from the business unit level.

\subsection{SEM-PLS}

The dataset was tested for normality to determine the appropriateness of parametric versus nonparametric testing procedures (Bollen and Stine, 1990; Ringle et al., 2012). As shown in Appendix B, Table B1, the skewness and kurtosis scores exceeded the value of two for many of the data points, evidencing univariate non-normality. Mardia's test of multivariate kurtosis produced an index of 180.6 and critical ratio of 31.1, being highly suggestive of multivariate non-normality (Byrne, 2010). Consequently, non-parametric test methods were required, with factor-analysis being inappropriate (Chin, 1998). SEM-PLS was used because it uses very general, soft distributional assumptions and non-parametric prediction-oriented model evaluation measures (Chin, 1998; Wold, 1982).

The analysis was performed with SmartPLS Version 3.00 M3. To report the measurement and structural model results we use the guidelines provided by Chin (2010) and Ringle et al. (2012). The significance of each effect was determined using bootstrapping with 1,000 samples (Chin and Dibbern, 2010). For the joint (H1c) and moderating (H2a, H2b, H3a, H3b) effects hypotheses the product indicator procedure was used, as is preferable in the presence of continuous variables (Henseler and Chin, 2010; Henseler and Fassott, 2010). With this product indicator procedure all 
variables except the joint and moderating variables created within the program are standardized (Henseler and Chin, 2010; Henseler and Fassott, 2010).

\subsection{Measurement model quality}

All first-order constructs were measured reflectively and so were tested for convergent and discriminant validities (Chin, 1998; Hulland, 1999). For convergent validity, as shown in Table B3 in Appendix B, indicator reliability was assessed by examining the significance of the construct loadings, and all were significant at $p<.001$. For construct reliability and validity, Table B2 indicates high internal consistency in terms of composite reliability (Dillon-Goldstein's $r h o \geq .60$ and Cronbach's $\alpha \geq .70$ ) (Bagozzi and Yi, 1988; Chin, 1998; Fornell and Larcker, 1981; Nunally, 1978). Convergent validity is confirmed as all average variances extracted (AVE) clearly exceed .50 (Fornell and Larcker, 1981). Discriminant validity of the construct indicators was examined by assessing the loading of each indicator on its first-order construct, relative to its loading on other constructs. Table B3 confirms that all first-order construct-specific loadings exceed .70 (Chin, 1998; Hulland, 1999) and that each indicator loading is highest for the relevant latent variable construct (Fornell and Larcker, 1981). Discriminant validity of the constructs is evidenced by all square roots of the AVE in the diagonal in Table B4 exceeding the correlations with the other constructs (Chin, 1998). ${ }^{3}$ In summary, all the standard measurement model quality requirements are met (Chin, 1998). ${ }^{4}$

\section{Results}

The hypotheses testing results are presented in Table 1. H1a predicts a positive effect of BI-planning functionality, which is supported $\left(\beta=.22, p<.01, f^{2}=.046\right)$. H1b expects a positive effect of BIreporting functionality, which is not supported $\left(\beta=.00, p=\right.$ n.s., $\left.f^{2}=.000\right)$. H1c is supported; it

3 The variance inflation factor scores for BI-PLANNING (1.94), BI-REPORTING (1.85), STRAT-MON (2.23) and FLEX (2.23) are all within a conservative tolerance range, indicating that multicollinearity is not a problem in the PLS model (Hair et al., 2013).

4 As discussed, performance measurement capability is a two-dimensional emergent construct. For the PLSSEM model in Table 1 the two loadings are: (1) interactive performance measurement capabilities .52 ( $p<$ $.01)$; and (2) diagnostic performance measurement capabilities $.54(p<.01)$. 
predicts a positive joint effect of BI-planning functionality and BI-reporting functionality $(\beta=.07, p<$ $\left..05, f^{2}=.010\right) . \mathrm{H} 2 \mathrm{a}$, which predicts that strategic momentum negatively moderates the effect of BIplanning functionality, is supported $\left(\beta=-.12, p<.10, f^{2}=.013\right)$. H2b expects that strategic momentum negatively moderates the effect of BI-reporting functionality and this is not supported $(\beta=$ $.13, p=$ n.s., $\left.f^{2}=.024\right)$. H3a proposed that organizational flexibility negatively moderates the effect of BI-planning functionality, and this hypothesis finds support $\left(\beta=-.08, p<.10, f^{2}=.01\right)$. H3b predicts that organizational flexibility negatively moderates the effect of BI-reporting functionality, an expectation that does not find support $\left(\beta=-.05, p=\right.$ n.s., $\left.f^{2}=.003\right)$.

\section{Table 1: Hypotheses testing results}

\section{Effects upon:}

\section{PERF-MEASURE-CAPABILITY}

\section{Betas:}

BI-PLANNING
BI-REPORTING
BI-PLANNING $\times$ BI-REPORTING
BI-PLANNING $\times$ STRAT-MOM
BI-REPORTING $x$ STRAT-MOM
BI-PLANNING $\times$ FLEXIBILITY
BI-REPORTING X FLEXIBILITY
STRAT-MOM
FLEXIBILITY

\section{R Squares:}

PERF-MEASURE-CAPABILITY

Hypo.

\section{F Squares:}

\begin{tabular}{lll} 
BI-PLANNING & $\mathrm{H} 1 \mathrm{a}$ & .046 \\
BI-REPORTING & $\mathrm{H} 1 \mathrm{~b}$ & .000 \\
BI-PLANNING x BI-REPORTING & $\mathrm{H} 1 \mathrm{c}$ & .010 \\
BI-PLANNING x STRAT-MOM & $\mathrm{H} 2 \mathrm{a}$ & .013 \\
BI-REPORTING x STRAT-MOM & $\mathrm{H} 2 \mathrm{~b}$ & .024 \\
BI-PLANNING X FLEXIBILITY & $\mathrm{H} 3 \mathrm{a}$ & .006 \\
BI-REPORTING x FLEXIBILITY & $\mathrm{H} 3 \mathrm{~b}$ & .003 \\
STRAT-MOM & & .040 \\
FLEXIBILITY & & .071 \\
& & 324 \\
\cline { 2 - 3 }
\end{tabular}

2-tailed tests: $p<.10 * ; p<.05 * * ; p<.01 * * *$ 
In summary, we find that BI-planning functionality has a positive main effect on performance measurement capabilities, which is negatively moderated by both strategic momentum and organizational flexibility. BI-reporting functionality has no main or moderated effects. For the positive 'joint' effect of BI-planning functionality and BI-reporting functionality, given that BIreporting functionality has no main effect, this effect is more accurately interpreted as BI-reporting functionality being a positive moderator of the effect of BI-planning functionality. ${ }^{5}$ Thus, the findings are twofold: BI-reporting functionality only enhances the usefulness of BI-planning functionality, and the usefulness of BI-planning functionality is reduced by organizational improvisation. Overall, we conclude that organizational improvisation reduces the usefulness of BI functionalities for performance measurement capabilities.

\section{Summary and conclusion}

Research at the intersection of information technology and management accounting is increasingly interested in BI systems. High functionality BI systems are commonly viewed as a stratagem for rapidly implementing robust performance measurement system designs that strengthen performance measurement capabilities. This study presents a deeper exploration of the relationship between the functionality of BI systems and performance measurement capabilities to consider whether the strong positive relationship found in prior literature is altered by organizational improvisation. We studied two variants of organizational improvisation: strategic momentum and organizational flexibility. A theoretical model was developed in which strategic momentum and organizational flexibility were each predicted to negatively moderate the main and joint effects of BI-planning functionality and BIreporting functionality upon performance measurement capabilities. The theoretical model was tested

5 We also ran a sensitivity test in which we dropped the interaction variable (of BI-planning functionality and BI-reporting functionality) finding that the magnitudes, $p$ values and effect sizes for BI-planning functionality and BI-reporting functionality were almost identical to those reported in Table 1 . This robustness test gives us even more confidence in our conclusion that BI-reporting functionality plays the role of moderator. 
using survey responses from 324 top-level managers from Australian-based business units with at least 100 employees.

The results indicate that the usefulness of BI functionalities in performance measurement capabilities is moderated by organizational improvisation. We find that BI-planning functionality drives performance measurement capability, but this relationship is negatively moderated by both strategic momentum and organizational flexibility. The results reveal that BI-reporting functionality only impacts performance measurement capabilities by positively moderating the effect of BI-planning functionality. We surmise that organizational improvisation reduces the importance of BI functionality for use in performance measurement capabilities. It appears that the more a firm has competences for organizational improvisation, the more that the managerial hierarchy tends to process minimal forms of performance measurement information - as are also available from lower functionality BI systems. It follows that, in firms that have competences for organizational improvisation and high functionality BI systems, there will be a mismatch such that, in using only minimal forms of performance measurement information, a managerial hierarchy would disregard the higher functionality features as surplus to requirements.

In terms of implications for practice, managers in firms with competences for organizational improvisation should be skeptical about the potential for achieving benefits from high-quality BIplanning and BI-reporting systems. This finding is especially salient given that vendors of high functionality BI systems often promote their systems as beneficial for flexibility and strategic decision-making (Kiron et al., 2012). For firms that do not have competences for organizational improvisation, the findings in this study reveal that higher functionality BI-reporting systems will be beneficial only if higher functionality BI-planning systems are also adopted. The broad arrays of realtime results data available with high functionality BI-reporting appear to only be beneficial when accompanied by variance feedback data that requires high functionality BI-planning systems be used. In light of the considerable adoption, running and maintenance costs of high functionality BI systems 
(Lee and Widener., 2016) these findings could be very informative for firms that are considering BI systems projects.

This study contributes a new perspective on how the effectiveness of BI systems quality can be moderated by organizational contextual factors. The prior research has studied a range of illuminating mediation models, focusing on the implementation, assimilation and use of BI systems, for achieving enhanced business performance outcomes (Chapman and Kihn, 2009; Elbashir et al., 2008, 2011, 2013; Lee and Widener, 2016; Peters et al., 2016; Prasad and Green, 2015). There are many important differences amongst those mediation models that enrich our understanding of $\mathrm{BI}$ and management control. Yet they share the inherent view that BI quality provides more performance measurement data elements, enabling additional information processing and fostering further learning and knowledge creation (e.g., Peters et al., 2016). In this study, the mediation chain link between BI functionality and performance measurement capabilities from Peters et al. (2016) was re-examined by introducing a potential moderating influence on this relationship. Similarly, there are opportunities for future research to extend other mediation chain links from prior literature by developing and testing theories based on moderating relationships. In relation to future research opportunities, a related shortcoming of our study is that it is unclear the extent to which the BI-reporting functionality construct overlaps with the digital dashboards construct used in Elbashir et al. $(2008,2011,2013)$ and in Lee and Widener (2016). Future research could further clarify these conceptual distinctions. Another potentially fruitful opportunity is to study how BI systems fit into a strategic enterprise risk management package (Arnold et al., 2015) - including the effects of dysfunctional moderating contingencies such as an overly calculative culture.

As with all research this study also has limitations, many of which stem from the research method used. First, the survey measures provide a static cross-sectional perspective, and without longitudinal research design causality between the constructs, cannot be proven but only inferred (Van der Stede, 2014). However, a robust longitudinal research design that captures both the pre- and post-adoption 
stages of a BI management control system would be near-impracticable (Van der Stede, 2014). While causality cannot be proven with cross-sectional survey research, the strength of causal inference is largely determined by the coherence and plausibility of the underlying theoretical explanations of the relationships (Van der Stede, 2014). The theoretical model underlying this study draws from established theoretical traditions, providing a relatively strong level of confidence in inferring causality from the effects identified. Second, the dataset was collected only from business units within Australia. Future studies that sourced data from other countries could shed light on the international generalizability of the findings, while comparative studies could examine the possibility of moderating effects of national culture (Van der Stede, 2017). Third, while the dataset spans many industries (which aids generalizability of the findings), there are insufficient responses to study possible inter-industry variations in the results. As Messner (2016) has detailed, there are rich research opportunities inherent in examining how management control system practices might vary across specific industry contexts. A fourth limitation is the small-size effects $(0.013$ or less) for the significant moderating effects results. However, Chin (1998) has discussed how such effect sizes can still be of consequence. In future, a small-sample qualitative study could explore reasons for these small-size effects (e.g., Stone, 2017).

Notwithstanding its limitations, this study reveals that BI-planning functionality (and not BI-reporting functionality) drives performance measurement capabilities, and that in the presence of organizational improvisation, higher BI functionalities have a reduced impact on performance measurement capabilities. This study demonstrates how BI research can progress by studying theory-derived moderating variables. In accord with the history of the broader management control systems research tradition (e.g., Chenhall, 2007), we view the BI literature stream as ripe for further extension by the inclusion of theory-derived moderating variables. By studying moderating variables new theories can be developed and new waves of research enabled (Chenhall, 2005). This opportunity likely applies strongly to research about information technologies (such as BI) and management control, because 
such relationships are often highly unpredictable and under-researched (Granlund, 2011; Sutton, 2006) and can unfold in surprising ways (Granlund et al., 2013). 


\section{References}

Abernethy, M. A. and P. Brownell (1999). The Role of Budgets in Organizations Facing Strategic Change: An Exploratory Study. Accounting, Organizations and Society 24 (3): 189-204.

Alavi, M. and D. E. Leidner (2001). Review: Knowledge Management and Knowledge Management Systems: Conceptual Foundations and Research Issues. MIS Quarterly 25 (1): 107-136.

Argote, L. (2013). Organizational Learning (2nd ed.). New York, NY: Springer.

Ariav, G. (1992). Information Systems for Managerial Planning and Control: A Conceptual Examination of their Temporal Structure. Journal of Management Information Systems 9 (2): $77-98$.

Arnold, V., T. Benford, J. Canada and S. Sutton (2015). Leveraging Integrated Information Systems to Enhance Strategic Flexibility and Performance: The Enabling Role of Enterprise Risk Management. International Journal of Accounting Information Systems 19 (1): 1-16.

Bagozzi, R. and Y. Yi (1988). On the Evaluation of Structural Equation Models. Journal of the Academy of Marketing Science 16 (1): 74-94.

Barki, H. and A. Pinsonneault (2005). A Model of Organizational Integration, Implementation Effort, and Performance. Organization Science 16 (2): 165-179.

Bingham, C. B. and K. M. Eisenhardt (2011). Rational Heuristics: The 'Simple Rules' that Strategists Learn from Process Experience. Strategic Management Journal 32 (13): 1437-1464.

Bisbe, J. and D. Otley (2004). The Effects of the Interactive Use of Management Control Systems on Product Innovation. Accounting, Organizations and Society 29 (8): 709-737.

Bollen, K. A. and R. Stine (1990). Direct and Indirect Effects: Classical and Bootstrap Estimates of Variability. Sociological Methodology 20 (1): 115-140.

Brown S. L. and K. M. Eisenhardt (1997). The Art of Continuous Change: Linking Complexity Theory and Time-paced Evolution in Relentlessly Shifting Organizations. Administrative Science Quarterly 42: 1-34.

Byrne, B. M. (2010). Structural Equation Modelling with AMOS (2nd ed.). Hove: Routledge.

Chandler, A. D. (1962). Strategy and Structure: Chapters in the History of American Enterprise. Boston, MA: MIT Press.

Chapman, C. and L. A. Kihn (2009). Information System Integration, Enabling Control and Performance. Accounting, Organizations and Society 34 (2): 151-169.

Chaudhuri, S., U. Dayal and V. Narasayya (2011). An Overview of Business Intelligence Technology. Communications of the ACM 54 (8): 88-98.

Chenhall, R. H. (2005). Integrative Strategic Performance Measurement Systems, Strategic Alignment of Manufacturing, Learning and Strategic Outcomes: An Exploratory Study. Accounting, Organizations and Society 30 (5): 395-422.

Chenhall, R. H. (2007). Theorising Contingencies in Management Control Systems Research. In: C. S. Chapman, A. G. Hopwood and M. D. Shields (Eds.), Handbook of Management Accounting Research - Volume 1. Amsterdam: Elsevier, pp. 163-206.

Chin, W. W. (1998). The Partial Least Squares Approach to Structural Equation Modeling. In G. A. Marcoulides (Ed.), Modern Methods for Business Research. Mahwah, NJ: Lawrence Erlbaum Associates, pp. 295-336.

Chin, W. W. (2010). How to Write Up and Report PLS Analysis. In V. Esposito Vinzi, W. W. Chin, J. Henseler and H. Wang (Eds.), Handbook of Partial Least Squares - Concepts, Methods and Applications in Marketing and Related Fields. Berlin: Springer, pp. 655-669. 
Chin, W. W. and J. Dibbern (2010). An Introduction to a Permutation Based Procedure for MultiGroup PLS Analysis: Results of Tests of Differences on Simulated Data and a Cross Cultural Analysis of the Sourcing of Information System Services between Germany and the USA. In V. Esposito Vinzi, W. W. Chin, J. Henseler and H. Wang (Eds.), Handbook of Partial Least Squares - Concepts, Methods and Applications in Marketing and Related Fields. Berlin: Springer, pp. 171-193.

Clark, T. D., M. C. Jones and C. P. Armstrong (2007). The Dynamic Structure of Management Support Systems: Theory Development, Research Focus and Direction. MIS Quarterly 31 (3): 579-615.

Cramer, D. (1997). Basic Statistics for Social Research - Step-by-step Calculations and Computer Techniques Using Minitab. London: Psychology Press.

Crossnan, M., M. P. Cunha, D. Vera and J. Cunha (2005). Time and Organizational Improvisation. Academy of Management Review 30 (1): 129-145.

Cunha, M. P., P. Neves, S. R. Clegg and A. Rego (2015). Tales of the Unexpected: Discussing Improvisational Learning. Management Learning 46 (5): 511-529.

Denison, D. R. and A. K. Mishra (1995). Toward a Theory of Organizational Culture and Effectiveness. Organization Science 6 (2): 204-223.

Dilla, W., D. J. Janvrin and R. Raschke. (2010). Interactive Data Visualization: New Directions for Accounting Information Systems Research. Journal of Information Systems 24 (2): 1-37.

Dillman, D. A. (2007). Mail and Internet Surveys: The Tailored Design Method. New York, NY: Wiley.

DiMaggio, P. (1997). Culture and Cognition. Annual Review of Sociology 23: 263-287.

Eisenhardt, K. M. and J. A. Martin (2000). Dynamic Capabilities: What are They? Strategic Management Journal 21 (10-11): 1105-1121.

Elbashir, M. Z., P. A. Collier and M. J. Davern (2008). Measuring the Effects of Business Intelligence Systems: The Relationship Between Business Process and Organizational Performance. International Journal of Accounting Information Systems 9 (3): 135-153.

Elbashir, M. Z., P. A. Collier and S. G. Sutton (2011). The Role of Organizational Absorptive Capacity in Strategic Use of Business Intelligence to Support Integrated Management Control Systems. The Accounting Review 86 (1): 155-184.

Elbashir, M. Z., P. A. Collier, S. G. Sutton, M. J. Davern and S. A. Leech (2013). Enhancing the Business Value of Business Intelligence: The Role of Shared Knowledge and Assimilation. Journal of Information Systems 27 (2): 87-105.

Fey, C. F. and D. R. Denison (2003). Organizational Culture and Effectiveness: Can American Theory Be Applied in Russia? Organization Science 14 (6): 686-706.

Fornell, C. and D. F. Larcker (1981). Evaluating Structural Equation Models with Unobservable Variables and Measurement Error. Journal of Marketing Research 18 (1): 39-50.

Galbraith, J. R. (1977). Organization Design. Reading, MA: Addison-Wesley.

Galunic, D. C. and K. M. Eisenhardt (1994). Renewing the Strategy-Structure-Performance Paradigm. Research in Organizational Behavior 16: 215-255.

Granlund, M. (2011). Extending AIS Research to Management Accounting and Control Issues - A Research Note. International Journal of Accounting Information Systems 12 (1): 3-19.

Granlund, M., J. Mouritsen and E. Vaasen (2013). On the Relations between Modern Information Technology, Decision Making and Management Control. International Journal of Accounting Information Systems 14 (4): 275-277. 
Henri, J. F. (2006). Management Control Systems and Strategy: A Resource-based Perspective. Accounting, Organizations and Society 31 (1): 529-558.

Henseler, J. and W. W. Chin (2010). A Comparison of Approaches for the Analysis of Interaction Effects Between Latent Variables Using Partial Least Squares Path Modelling. Structural Equation Modelling: A Multidisciplinary Journal 17 (1): 82-109.

Henseler, J. and G. Fassott (2010). Testing Moderating Effects in PLS Path Models: An Illustration of Available Procedures. In V. Esposito Vinzi, W. W. Chin, J. Henseler and H. Wang (Eds.), Handbook of Partial Least Squares - Concepts, Methods and Applications in Marketing and Related Fields. Berlin: Springer-Verlag, pp. 713-735.

Huber, G. P. (1991). Organizational Learning: The Contributing Processes and the Literatures. Organization Science 2 (1): 88-115.

Hulland, J. (1999). The Use of Partial Least Square (PLS) in Strategic Management Research: A Review of Four Recent Studies. Strategic Management Journal 20 (2): 195-204.

Kanoche, K. and M. P. Cunha (2001). Minimal Structures: From Jazz Improvisation to Product Innovation. Organization Studies 22 (5): 733-764.

Kiron, D., P. K. Prentice and R. B. Ferguson (2012). Innovating with Analytics. MIT Sloan Management Review 54 (1): 41-52.

Lee, M. T. and S. K. Widener (2016). The Performance Effects of Using Business Intelligence Systems for Exploitation and Exploration Learning. Journal of Information Systems 30 (3): $1-31$.

Libby, T. and R. M. Lindsay (2010). Beyond Budgeting or Budgeting Reconsidered? A Survey of North American Budgeting Practice. Management Accounting Research 21 (1): 56-75.

Malmi, T. and D. A. Brown (2008). Management Control Systems as a Package - Opportunities, Challenges and Research Directions. Management Accounting Research 19 (4): 287-300.

McGrath, R. M. (2006). Beyond Contingency: From Structure to Structuring in the Design of the Contemporary Organization. In S. R. Clegg, C. Hardy, T. B. Lawrence and W. R. Nord (Eds.), The Sage Handbook of Organization Studies. London: Sage Publications, pp. 541-576.

Merchant, K. A. and W. A. Van der Stede (2012). Management Control Systems: Performance Measurement, Evaluation and Incentives (3rd ed.). Harlow: Pearson Education.

Messner, M. (2016). Does Industry Matter? How Industry Context Shapes Management Accounting Practice. Management Accounting Research 31 (1): 103-111.

Miller, D. and P. H. Friesen (1980). Momentum and Revolution in Organizational Adaptation. Academy of Management Journal 23: 591-614.

Mintzberg, H. (1987) Crafting Strategy. Harvard Business Review July-August: 66-75.

Naranjo-Gil, D. and F. Hartmann (2007). Management Accounting Systems, Top Management Team Heterogeneity and Strategic Change. Accounting, Organizations and Society 32 (7): 735-756.

Netemeyer, R. G., W. O. Bearden and S. Sharma (2003). Scaling Procedures: Issues and Applications. Thousand Oaks, CA: Sage.

Newell, A. and H. A. Simon (1972). Human Problem Solving. Englewood Cliffs, NJ: Prentice Hall.

Nunnally, J. C. (1978). Psychometric Theory. New York, NY: McGraw-Hill.

Orlikowksi, W. J. (1991). Integrated Information Environment or Matrix of Control?: The Contradictory Implications of Information Technology. Accounting, Management and Information Technology 1 (1): 9-42 
Orlikowski, W. J. (1996). Improvising Organizational Transformation Over Time: A Situated Change Perspective. Information Systems Research 7 (1): 63-92.

Peters, M. D., B. Wieder, S. G. Sutton and J. Wakefield (2016). Business Intelligence Systems Use in Performance Measurement Capabilities: Implications for Enhanced Competitive Advantage. International Journal of Accounting Information Systems 21: 1-17.

Podsakoff, P. M., S. B. MacKenzie and N. P. Podsakoff (2012). Sources of Method Bias in Social Science Research and Recommendations on How to Control It. Annual Review of Psychology 63: 539-569.

Podsakoff, P. M. and D. W. Organ (1986). Self-reports in Organizational Research: Problems and Prospects. Journal of Management 12 (4): 531-544.

Prasad, A. and P. Green (2015). Organizational Competencies and Dynamic Accounting Information System Capability: Impact on AIS Processes and Firm Performance. Journal of Information Systems 29 (3): 123-149.

Ringle, C. M., M. Sarstedt and D. W. Straub (2012). Editor's Comments: A Critical Look at the Use of PLS-SEM in MIS Quarterly. MIS Quarterly 36 (1): iii-xiv.

Simons, R. (1995). Levers of Control: How Managers Use Innovative Control Systems to Drive Strategic Renewal. Boston, MA: Harvard University Press.

Stone, D. N. (2017). The "New Statistics" and Nullifying the Null: Twelve Actions for Improving Quantitative Accounting Research Quality and Integrity. Accounting Horizons In-Press.

Suddaby, R. (2010). Editor's Comments: Construct Clarity in Theories of Management and Organization. Academy of Management Review 35 (3): 346-357.

Sutton, S. G. (2006). Enterprise Systems and the Re-shaping of Accounting Systems: A Call for Research. International Journal of Accounting Information Systems 7 (1): 1-6.

Thompson, J. D. (1967). Organizations in Action. New York, NY: McGraw-Hill.

Tourangeau, R., L. J. Rips and K. Rasinski (2000). The Psychology of Survey Response. Cambridge: Cambridge University Press.

Turner, S. F., W. Mitchell and R. A. Bettis (2013). Strategic Momentum: How Experience Shapes Temporal Consistency of Ongoing Innovation. Journal of Management 39 (7): 1855-1890.

Van der Stede, W. A. (2014). A Manipulationist View of Causality on Cross-sectional Research. Accounting, Organizations and Society 39 (7): 567-574.

Van der Stede, W. A. (2017). "Global” Management Accounting Research: Some Reflections. Journal of International Accounting Research 16 (2): 1-8.

Volberda, H. W. (1996). Toward the Flexible Form: How to Remain Vital in Hypercompetitive Environments. Organization Science 7 (4): 359-374.

Weber, K. and M. T. Dacin (2011). The Cultural Construction of Organizational Life: Introduction to the Special Issue. Organization Science 22 (2): 287-298.

Weick, K. E. (1989). Organized Improvisation: 20 Years of Organizing. Communication Studies 40: 241-248.

Wetzels, M., G. Odekerken-Schröder and C. van Oppen (2009). Using PLS Path Modeling for Assessing Hierarchical Construct Models: Guidelines and Empirical Illustration. MIS Quarterly 33 (1): 177-195.

Widener, S. K. (2007). An Empirical Analysis of the Levers of Control Framework. Accounting, Organization and Society 32 (7): 757-788. 
Wold, H. (1982). Soft Modeling: The Basic Design and Some Extensions. In K. G. Joreskog and H. Wold (Eds.), Systems Under Indirect Observations: Causality, Structure, Prediction. Amsterdam: North-Holland, pp. 1-54. 


\section{Appendix A: Survey items}

\begin{tabular}{ll}
\hline Construct & Questions and indicators \\
\hline BI-reporting & Our management reporting and analysis systems [strongly disagree (1); strongly agree (5)]: \\
functionality & 1. have sophisticated formats and presentation features. \\
& 2. have highly interactive reporting features. \\
& 3. are very easy to use and navigate by all users. \\
& 4. $\quad$ have rapid response and refresh times. \\
\hline BI-planning & Our planning, budgeting, and forecasting systems [strongly disagree (1); strongly agree (5)]: \\
functionality & 1. have rapid response and refresh times. \\
& 2. are very quickly updated with actual and base-level information. \\
& 3. allow forecasts and budgets to be quickly created and revised. \\
& 4. allow sophisticated planning models to be easily implemented and changed. \\
\hline
\end{tabular}

Strategic Please indicate the degree to which you agree or disagree with the following statements regarding momentum your business unit [strongly disagree (1); strongly agree (7)]:

1. It is easy to reach consensus, even on difficult issues.

2. People from different organizational units still share a common perspective.

3. This organization has long-term purpose and direction.

4. There is widespread agreement about goals of this organization.

Organizational Please indicate the degree to which you agree or disagree with the following statements regarding flexibility $\quad$ your business unit [strongly disagree (1); strongly agree (7)]:

1. This organization is constantly improving compared with its competitors in many dimensions.

2. Decisions are usually made at the level where the best information is available.

3. Customer comments and recommendations often lead to changes in this organization.

4. This organization encourages and rewards those who take risk.

Diagnostic How intensively do senior managers use profit planning activities in your business unit to performance [strongly disagree (1); strongly agree (5)]:

measurement $\quad$ 1. follow up on targets.

capabilities 2 . track progress towards goals.

3. review significant deviations.

4. evaluate and control subordinates.

How intensively do senior managers use non-financial key performance indicators in your business unit to [strongly disagree (1); strongly agree (5)]:

1. follow up on targets.

2. track progress towards goals.

3. review significant deviations.

4. evaluate and control subordinates.

Interactive performance measurement capabilities
Please indicate the degree to which you agree or disagree with the statements regarding your business unit [strongly disagree (1); strongly agree (7)]:

1. Senior managers meet and discuss profit planning information frequently (e.g., weekly)

2. Middle and senior managers meet and discuss profit planning information frequently (e.g., weekly)

3. Profit planning meetings always include consideration of multiple alternatives and scenarios

4. Strategic business changes are always assessed in profit planning meetings

Please indicate the degree to which you agree or disagree with the statements regarding your business unit [strongly disagree (1); strongly agree (7)]:

1. Senior managers constantly interact with peers to discuss non-financial KPIs

2. Middle managers are continually involved in discussing non-financial KPIs with senior managers

3. Every discussion of non-financial KPIs involves intensive review and revision of action plans

4. Significant business development opportunities are a key focus in all discussions of nonfinancial KPIs 


\section{Appendix B: Measurement model reliability and validity tests}

Table B1: Descriptive statistics.

\begin{tabular}{|c|c|c|c|c|}
\hline $\begin{array}{l}\text { Constructs }{ }^{\mathrm{a}} \text { and indicators }(\mathrm{N}=324) \\
\text { (Likert scale end-points in brackets) }\end{array}$ & Mean & $\begin{array}{l}\text { Standard } \\
\text { deviation }\end{array}$ & $\begin{array}{r}\text { Skew/ } \\
\mathbf{S E}_{\text {skew }}{ }^{6}\end{array}$ & $\begin{array}{c}\text { Kurtosis/ } \\
\text { SE }_{\text {kurt }}{ }^{c}\end{array}$ \\
\hline BI-reporting functionality (1-5) & 2.95 & 0.90 & -0.59 & -1.06 \\
\hline Format and presentation features $(1-5)$ & 3.03 & 1.05 & -1.18 & -2.19 \\
\hline Interactive reporting (1-5) & 2.76 & 1.03 & 0.96 & -1.89 \\
\hline Ease of use (1-5) & 2.96 & 1.02 & -0.01 & -1.86 \\
\hline Response and refresh time (1-5) & 3.07 & 1.05 & -0.77 & -2.33 \\
\hline BI-planning functionality (1-5) & 2.88 & 0.97 & 0.32 & -2.24 \\
\hline Response and refresh time $(1-5)$ & 2.95 & 1.07 & -0.18 & -2.61 \\
\hline Actuals update speed (1-5) & 3.03 & 1.10 & -0.50 & -3.10 \\
\hline Forecast speed (1-5) & 2.94 & 1.08 & -0.12 & -3.25 \\
\hline Planning model sophistication (1-5) & 2.61 & 1.06 & 1.83 & -2.04 \\
\hline Diagnostic Performance Measurement Capability (1-5) & 3.76 & 0.70 & -6.05 & 5.89 \\
\hline Diagnostic profit-planning (1-5) & 3.90 & 0.78 & -7.53 & 6.47 \\
\hline Follow up on targets (1-5) & 3.98 & 0.86 & -6.96 & 4.64 \\
\hline Track progress towards goals $(1-5)$ & 4.09 & 0.85 & -8.16 & 6.10 \\
\hline Review significant deviations (1-5) & 4.06 & 0.90 & -8.08 & 4.59 \\
\hline Evaluate and control subordinates (1-5) & 3.48 & 0.98 & -4.34 & -0.14 \\
\hline Diagnostic non-financial KPIs (1-5) & 3.57 & 0.86 & -5.01 & 2.09 \\
\hline Follow up on targets $(1-5)$ & 3.62 & 0.93 & -5.21 & 1.09 \\
\hline Track progress towards goals $(1-5)$ & 3.69 & 0.90 & -5.80 & 2.29 \\
\hline Review significant deviations (1-5) & 3.62 & 0.96 & -3.86 & -0.30 \\
\hline Evaluate and control subordinates (1-5) & 3.37 & 0.96 & -2.58 & -0.84 \\
\hline Interactive Performance Measurement Capability (1-7) & 4.46 & 1.17 & -3.04 & 0.22 \\
\hline Interactive profit-planning (1-7) & 4.46 & 1.37 & -3.33 & -1.02 \\
\hline Senior management interaction $(1-7)$ & 4.50 & 1.84 & -2.93 & -3.70 \\
\hline Senior/middle management interaction (1-7) & 4.03 & 1.79 & -0.43 & -3.66 \\
\hline Consideration of alternatives/scenarios (1-7) & 4.63 & 1.66 & -4.31 & -1.52 \\
\hline Strategic business change assessment (1-7) & 4.68 & 1.69 & -4.11 & -2.13 \\
\hline Interactive non-financial KPIs (1-7) & 4.46 & 1.28 & -3.13 & -0.28 \\
\hline Senior management interaction (1-7) & 4.90 & 1.44 & -4.93 & 0.10 \\
\hline Senior/middle management interaction (1-7) & 4.67 & 1.44 & -3.79 & -0.96 \\
\hline Consideration of alternatives/scenarios (1-7) & 4.00 & 1.43 & -0.15 & -2.09 \\
\hline Strategic business change assessment (1-7) & 4.30 & 1.49 & 1.91 & -2.42 \\
\hline Strategic Momentum (1-7) & 5.02 & 1.14 & -4.87 & 0.94 \\
\hline Consensus on difficult issues (1-7) & 4.55 & 1.33 & -4.01 & -0.48 \\
\hline Shared common perspective (1-7) & 4.83 & 1.32 & -4.47 & -0.19 \\
\hline Long-term purpose and direction (1-7) & 5.50 & 1.32 & -7.01 & 3.91 \\
\hline Widespread agreement about goals (1-7) & 5.17 & 1.41 & -5.27 & 0.30 \\
\hline Organizational Flexibility $(1-7)$ & 4.80 & 1.06 & -4.59 & 1.13 \\
\hline Constantly improving versus competitors (1-7) & 5.14 & 1.24 & -5.21 & 1.75 \\
\hline Decentralised decision making (1-7) & 5.03 & 1.32 & -5.58 & 2.07 \\
\hline Customer led change orientation (1-7) & 4.69 & 1.32 & -2.14 & -1.57 \\
\hline Encouragement and reward for risk taking $(1-7)$ & 4.25 & 1.42 & -2.14 & -1.76 \\
\hline
\end{tabular}

${ }^{a}$ The scores for the constructs are based on the unstandardized latent variable scores.

b Sample skewness divided by standard error of skewness (SES), with test scores $>2$ or $<-2$ suggesting significant positive or negative skew (Cramer, 1997).

c Sample kurtosis divided by standard error of kurtosis (SEK), with test scores $>2$ or $<-2$ suggesting significant positive or negative kurtosis (Cramer, 1997). 
Table B2: Indicator reliability, construct reliability and construct validity.

\begin{tabular}{lccc}
\hline Constructs $(\mathrm{N}=324)$ & Cronbach's $\alpha^{\mathrm{a}}$ & $\begin{array}{c}\text { Composite } \\
\text { Reliability }(\rho)^{\mathrm{a}}\end{array}$ & AVE $^{\mathrm{b}}$ \\
\hline BI-reporting functionality & .92 & .89 & .75 \\
BI-planning functionality & .95 & .93 & .82 \\
Diagnostic profit-planning & .93 & .89 & .76 \\
Diagnostic non-financial KPIs & .95 & .93 & .83 \\
Interactive profit-planning & .87 & .79 & .62 \\
Interactive non-financial KPIs & .93 & .91 & .78 \\
Strategic Momentum & .86 & .91 & .71 \\
Organizational Flexibility & .81 & .88 & .64 \\
\hline
\end{tabular}

${ }^{a}$ Internal consistency: All composite reliability (Dillon-Goldstein's $\rho$ ) indices are $\geq .60$ (Bagozzi and Yi, 1988) and all Cronbach's alpha indices are $\geq .70$ (Nunnally, 1978).

${ }^{\mathrm{b}}$ Convergent validity: All average variance extracted (AVE) indices are $\geq .50$ (Fornell and Larcker, 1981). 
Table B3: PLS loadings and cross-loadings.

\begin{tabular}{|c|c|c|c|c|c|c|c|c|}
\hline First-order constructs/indicators $(\mathrm{n}=324)$ & 1. & 2. & 3. & 4. & 5. & 6. & 7. & 8. \\
\hline \multicolumn{9}{|l|}{ 1. BI-reporting functionality } \\
\hline Format and presentation features & .88 & .56 & .18 & .18 & .16 & .20 & .18 & .21 \\
\hline Interactive reporting & .90 & .56 & .20 & .21 & .22 & .24 & .17 & .25 \\
\hline Ease of use & .84 & .58 & .18 & .14 & .15 & .19 & .21 & .28 \\
\hline Response and refresh time & .85 & .62 & .15 & .16 & .19 & .22 & .22 & .25 \\
\hline \multicolumn{9}{|l|}{ 2. BI-planning functionality } \\
\hline Response and refresh time & .57 & .90 & .30 & .29 & .32 & .34 & .33 & .31 \\
\hline Actuals update speed & .59 & .93 & .32 & .31 & .27 & .35 & .33 & .29 \\
\hline Forecast speed & .63 & .91 & .31 & .25 & .29 & .29 & .27 & .28 \\
\hline Planning model sophistication & .62 & .88 & .28 & .26 & .30 & .31 & .28 & .28 \\
\hline \multicolumn{9}{|l|}{ 3. Diagnostic profit-planning } \\
\hline Follow up on targets & .16 & .29 & .89 & .41 & .58 & .50 & .43 & .41 \\
\hline Track progress towards goals & .18 & .28 & .91 & .40 & .54 & .46 & .40 & .38 \\
\hline Review significant deviations & .17 & .30 & .88 & .46 & .53 & .47 & .39 & .37 \\
\hline Evaluate and control subordinates & .19 & .30 & .80 & .49 & .47 & .47 & .34 & .37 \\
\hline \multicolumn{9}{|l|}{ 4. Diagnostic non-financial KPIs } \\
\hline Follow up on targets & .18 & .26 & .44 & .93 & .35 & .73 & .42 & .42 \\
\hline Track progress towards goals & .16 & .24 & .43 & .93 & .29 & .68 & .42 & .44 \\
\hline Review significant deviations & .18 & .30 & .48 & .92 & .34 & .69 & .43 & .43 \\
\hline Evaluate and control subordinates & .22 & .33 & .50 & .88 & .37 & .66 & .40 & .46 \\
\hline \multicolumn{9}{|l|}{ 5. Interactive profit-planning } \\
\hline Senior management interaction & .14 & .25 & .49 & .22 & .77 & .37 & .21 & .26 \\
\hline Senior/middle management interaction & .14 & .19 & .46 & .24 & .80 & .39 & .23 & .33 \\
\hline Consideration of alternatives/scenarios & .23 & .29 & .52 & .34 & .83 & .52 & .38 & .42 \\
\hline Strategic business change assessment & .14 & .29 & .44 & .35 & .74 & .49 & .48 & .40 \\
\hline \multicolumn{9}{|l|}{ 6. Interactive non-financial KPIs } \\
\hline Senior management interaction & .16 & .30 & .47 & .70 & .43 & .89 & .48 & .45 \\
\hline Senior/middle management interaction & .15 & .29 & .50 & .70 & .48 & .90 & .45 & .44 \\
\hline Consideration of alternatives/scenarios & .29 & .37 & .49 & .64 & .57 & .90 & .41 & .44 \\
\hline Strategic business change assessment & .28 & .30 & .46 & .63 & .52 & .85 & .42 & .46 \\
\hline \multicolumn{9}{|l|}{ 7. Strategic Momentum } \\
\hline Consensus on difficult issues & .19 & .27 & .34 & .29 & .35 & .38 & .75 & .56 \\
\hline Shared common perspective & .24 & .33 & .38 & .39 & .36 & .45 & .86 & .62 \\
\hline Long-term purpose and direction & .14 & .24 & .38 & .43 & .34 & .42 & .85 & .65 \\
\hline Widespread agreement about goals & .19 & .28 & .40 & .42 & .37 & .42 & .89 & .64 \\
\hline \multicolumn{9}{|l|}{ 8. Organizational Flexibility } \\
\hline Constantly improving versus competitors & .21 & .24 & .36 & .41 & .35 & .42 & .64 & .85 \\
\hline Decentralized decision making & .24 & .26 & .39 & .38 & .45 & .46 & .67 & .83 \\
\hline Customer led change orientation & .25 & .24 & .26 & .38 & .29 & .35 & .48 & .74 \\
\hline Encouragement and reward for risk taking & .23 & .29 & .38 & .36 & .34 & .38 & .54 & .78 \\
\hline
\end{tabular}

All loadings on the expected constructs (in bold) are significant at $p<.001$. All items load strongly on the expected construct whilst loading only weakly on the other constructs. 
Table B4: Correlation/path coefficient matrix and discriminant validity assessment.

\begin{tabular}{llllll}
\hline Constructs $(\mathrm{N}=324)$ & 1. & 2. & 3. & 4. & 5. \\
\hline 1. BI-reporting functionality & $\mathbf{. 8 7}$ & & & & \\
2. BI-planning functionality & .67 & $\mathbf{. 9 0}$ & & & \\
3. Performance measurement capabilities & .26 & .40 & .71 & & \\
4. Strategic momentum & .23 & .33 & .56 & $\mathbf{. 8 4}$ & \\
5. Organizational flexibility & .28 & .32 & .57 & .73 & $\mathbf{. 8 0}$ \\
\hline
\end{tabular}

Discriminant validity: Bold numbers on the diagonal are the square root of the AVE of each construct; all values are greater than those in the corresponding rows and columns. 